\title{
Why Are CASTA and CARS Results Different? Analysis of CASTA Data from Korea and Hong Kong
}

\author{
Jong S. Kim, Bum Joon Kim \\ Department of Neurology, University of Ulsan, Asan Medical Center, Seoul, Korea
}

Dear Sir:

Cerebrolysin is a neuropeptide preparation, which mimics the action of endogenous neurotrophic factors. ${ }^{1}$ In animal models, Cerebrolysin stabilizes the structural integrity of cells by inhibiting calpain, reduces the number of apoptotic cells and decreases infarct volume and edema formation. Furthermore, Cerebrolysin promotes neurogenesis and supports the self-repair mechanism of the brain, ${ }^{2,3}$ resulting in improved functional recovery.

The Cerebrolysin Acute Stroke Treatment in Asia (CASTA) trial was a multicenter, randomized, double-blind, placebo-controlled study that examined the efficacy of Cerebrolysin on the recovery of stroke patients. ${ }^{4}$ Patients were recruited from 51 centers located in China (1,024 patients), Hong Kong (4 patients), South Korea (16 patients), and Myanmar (26 patients). The confirmatory endpoint showed no significant difference between the patients treated with Cerebrolysin and those receiving placebo. More recently, however, investigators from the Cerebrolysin And Recovery after Stroke (CARS) study reported that Cerebrolysin significantly improved neurologic recovery in ischemic stroke patients. ${ }^{5}$

The aim of our present research was to investigate possible reasons for the different outcome of the CASTA and CARS trials on the basis of (1) the study designs and (2) a re-analysis of CASTA data. As summarized in Table 1, there are several notable differences in the study design of the two studies. First, while the CASTA trial focused on the National Institutes of Health Stroke Scale (NIHSS) and enrolled patients with various levels of functional disability, the CARS study defined patients by their motor deficits and included patients with more severe disturbances. Most likely, the design took the post-hoc data of the CASTA study into consideration as the more severe subgroup with a baseline NIHSS score $>12$ showed significant improvement in their NIHSS scores $(P=0.04)$ at day 90 . This may be one reason why the CARS study avoided the ceiling effect observed in CASTA. Second, in the CARS study treatment was started 24-72 hours post-stroke as compared to 12 hours in the CASTA trial, which allowed to exclude patients with progressive or fluctuating stroke. Third, while Cerebrolysin was given over 10 days in the CASTA trial, it was administered over 21 days in the CARS trial. This allowed the recovering patients to benefit longer from the neurorestorative action of Cerebrolysin. Finally, a standardized rehabilitation program was strictly applied to CARS patients whereas this was not mandatory in the CASTA study.

We examined the last aspect by re-assessing data obtained in the CASTA trial. The majority of enrolled patients did not receive rehabilitation therapy (personal communication). However, Korean and Hong Kong centers had a policy for early mobilization and rehabilitation as well as the facilities to implement it. It also was noticed that some of the Korean and Hong Kong CASTA patients did not receive active rehabilitation whereas it was mandatory for all CARS patients. Therefore, we could use the CASTA data from Korea and Hong Kong to examine whether early rehabilitation enhances the efficacy of Cerebrolysin in stroke patients.

Among the CASTA patients enrolled in Korea and Hong Kong, we selected and analyzed the data for patients who had functional deficits that needed rehabilitation therapy as defined by a score of 2-5 on the modified Rankin Scale (mRS) at day 5. We grouped the patients and compared them as follows: 1) patient received neither rehabilitation nor Cerebrolysin, 2) patient received either Cerebrolysin or rehabilitation, and 3) patient re- 
Table 1. Differences in study design between the CASTA and CARS study

\begin{tabular}{|c|c|c|c|}
\hline & CASTA & CARS & Comments on CARS \\
\hline Included patients & NIHSS score 6-22 & $\begin{array}{l}\text { Ischemic supratentorial strokes volume }>4 \mathrm{~cm}^{3} \\
\text { Action Research Arm Test score }<50 \\
\text { Goodglass and Kaplan Communication Scale score }>2\end{array}$ & $\begin{array}{l}\text { Focused on disturbances of upper motor } \\
\text { function }\end{array}$ \\
\hline Excluded patients & $\begin{array}{l}\text { Patients with neurological signs } \\
\text { /symptoms likely to resolve } \\
\text { within } 24 \text { hours }\end{array}$ & Progressive or unstable stroke & Focused on recovery from stable deficit \\
\hline Medication & $\begin{array}{l}\text { Once daily for } 10 \text { days starting } \\
<12 \text { hours of stroke onset }\end{array}$ & $\begin{array}{l}\text { Once daily for } 21 \text { days starting } 24-72 \text { hours after } \\
\text { stroke onset }\end{array}$ & $\begin{array}{l}\text { Focused on drug effect during } \\
\text { restorative stage with longer duration } \\
\text { of therapy }\end{array}$ \\
\hline Primary outcome & $\begin{array}{l}\text { Combined results of } \mathrm{Bl}, \mathrm{mRS} \text {, } \\
\text { and the NIHSS evaluated in a } \\
\text { global test }\end{array}$ & Action Research Arm Test & $\begin{array}{l}\text { Focused on upper motor function } \\
\text { improvement }\end{array}$ \\
\hline Rehabilitation & Not mentioned & $\begin{array}{l}\text { Standardized rehabilitation program for } 21 \text { days, } \\
\text { beginning within } 48-72 \text { hours after stroke onset } \\
\text { ( } 5 \mathrm{~d} / \text { wk for } 2 \mathrm{~h} / \mathrm{d}) \text {. }\end{array}$ & $\begin{array}{l}\text { Synergistic effects with rehabilitation } \\
\text { to be seriously considered }\end{array}$ \\
\hline
\end{tabular}

BI, Barthel Index; mRS, modified Rankin Scale; NIHSS, National Institutes of Health Stroke Scale.

Table 2. Characteristics and outcomes of stroke patients according to early rehabilitation and use of cerebrolysin

\begin{tabular}{|c|c|c|c|c|}
\hline & $\begin{array}{l}\text { None } \\
(n=3)\end{array}$ & $\begin{array}{c}\text { Cerebrolysin or } \\
\text { rehabilitation }(n=8)\end{array}$ & $\begin{array}{l}\text { Cerebrolysin and } \\
\text { rehabilitation }(n=4)\end{array}$ & $P$ \\
\hline Age (year) & 71.3 [7.02] & $63.6[7.3]$ & 71.3 [13.3] & 0.31 \\
\hline Male & 2 (66.7) & $6(75.0)$ & 2 (50.0) & 0.69 \\
\hline Hypertension & $0(0)$ & $5(62.5)$ & $1(25.0)$ & 0.13 \\
\hline Diabetes & $1(33.3)$ & $3(37.5)$ & $1(25.0)$ & 0.91 \\
\hline Hyperlipidemia & $1(33.3)$ & $0(0)$ & $0(0)$ & 0.12 \\
\hline Coronary disease & $1(33.3)$ & $1(12.5)$ & $1(25.0)$ & 0.71 \\
\hline Previous stroke & $0(0)$ & $1(12.5)$ & $0(0)$ & 0.63 \\
\hline \multicolumn{5}{|l|}{ Day 1} \\
\hline $\mathrm{mRS}^{*}$ & $3.0[3.0,4.0]$ & $4.0[4.0,4.75]$ & $4.0[3.25,4.0]$ & 0.17 \\
\hline NIHSS & $9.0[4.4]$ & $13.0[5.3]$ & $6.5[0.6]$ & 0.08 \\
\hline $\mathrm{BI}$ & 36.7 [27.5] & $20.0[13.1]$ & $41.25[13.8]$ & 0.12 \\
\hline \multicolumn{5}{|l|}{ Day 90} \\
\hline $\mathrm{mRS}^{*}$ & $3.0[2.0,6.0]$ & $4.0[3.25,5.0]$ & $1.5[1.0,2.75]$ & 0.03 \\
\hline NIHSS & $16.7[22.0]$ & $11.3[5.8]$ & $3.0[1.4]$ & 0.23 \\
\hline $\mathrm{BI}$ & $58.3[51.1]$ & 36.9 [30.9] & $91.3[4.8]$ & 0.048 \\
\hline \multicolumn{5}{|l|}{ Difference $^{+}$} \\
\hline $\mathrm{mRS}^{*}$ & $0.0[-1.0,2.0]$ & $0.0[0.0,0.0]$ & $-2.00[-1.25,-2.75]$ & 0.02 \\
\hline NIHSS & $7.67[17.6]$ & $-1.75[6.14]$ & $-3.50[1.0]$ & 0.23 \\
\hline $\mathrm{BI}$ & $21.7[25.2]$ & $16.7[19.6]$ & $48.8[13.2]$ & 0.06 \\
\hline
\end{tabular}

Results expressed as a number (\% column), mean [SD], or median [interquartile range].

BI, Barthel Index; mRS, modified Rankin Scale; NIHSS, National Institutes of Health Stroke Scale.

${ }^{*} \mathrm{mRS}$ was evaluated by Kruskal-Wallis test by ranks; ${ }^{+}$Difference represents the difference between Day 90 and Day 1.

ceived both rehabilitation and Cerebrolysin; these patients received rehabilitation therapy during the same period as Cerebrolysin treatment. Out of 19 patients (16 Korean and 3 Hong Kong patients), we excluded 4 patients ( 3 from Korea and 1 from Hong Kong) because of follow-up loss. The remaining 15 patients were analyzed; 3 patients received none, 8 patients received either rehabilitation or Cerebrolysin (rehabilitation only $=7$ and Cerebrolysin only $=1$ ), and 4 patients received both rehabilitation and Cerebrolysin.
Among the three groups, we found no significant differences in their baseline characteristics including their mRS, NIHSS, and BI scores. However, the mRS score of patients receiving both rehabilitation and Cerebrolysin was significantly improved at day 90 as compared to those who received none, or only one of the treatments (mRS 0-2: both 75\%, none 0\%, one 0\%; $P=0.006$ ). In addition, the $\mathrm{BI}$ score at 90 days was also significantly higher in patients receiving both rehabilitation and Cerebrolysin $(P=$ 0.048; Table 2). 
A major limitation of our post-hoc analysis is the small number of patients. Additionally, we do not know why some Korean and Hong Kong CASTA study patients did not receive rehabilitation therapy. Therefore, our data should be interpreted with caution. However, our data - being in line with the findings of the CARS study - suggest that patients benefit especially from a double intervention that combines early rehabilitation and Cerebrolysin treatment. This combination treatment may have synergistic effects on the improvement of neurological recovery $y^{6,7}$ and should be investigated in further studies.

\section{Acknowledgments}

We sincerely thank Dr. WS Poon (Chinese University of Hong Kong), Dr. KC Chung, Dr. DI Chang, and Dr. SH Heo (Kyung-Hee University Hospital) for their assistance in obtaining the patients' data.

\section{References}

1. Rockenstein $E_{1}$ Mante M, Adame A, Crews L, Moessler H, Masliah E. Effects of Cerebrolysin ${ }^{\text {TM }}$ on neurogenesis in an APP transgenic model of Alzheimer's disease. Acta Neuropathol 2007; 113:265-275.

2. Ren J, Sietsma D, Qiu S, Moessler H, Finklestein SP. Cerebrolysin enhances functional recovery following focal cerebral infarction in rats. Restor Neurol Neurosci 2007;25:25-31.

3. Zhang C, Chopp M, Cui Y, Wang L, Zhang R, Zhang L, et al. Cerebrolysin enhances neurogenesis in the ischemic brain and improves functional outcome after stroke. J Neurosci Res 2010; 88:3275-3281.

4. Heiss WD, Brainin M, Bornstein NM, Tuomilehto J, Hong Z, Cerebrolysin Acute Stroke Treatment in Asia (CASTA) Investigators. Cerebrolysin in patients with acute ischemic stroke in Asia: results of a double-blind, placebo-controlled randomized trial. Stroke 2012;43:630-636.

5. Muresanu DF, Heiss WD, Hoemberg V, Bajenaru O, Popescu CD, Vester JC, et al. Cerebrolysin and Recovery After Stroke (CARS): a randomized, placebo-controlled, double-blind, multicenter trial. Stroke 2016;47:151-159.

6. Johansson BB. Brain plasticity and stroke rehabilitation. The Willis lecture. Stroke 2000;31:223-230.

7. Mang CS, Campbell KL, Ross CJ, Boyd LA. Promoting neuroplasticity for motor rehabilitation after stroke: considering the effects of aerobic exercise and genetic variation on brain-derived neurotrophic factor. Phys Ther 2013;93:1707-1716.

Correspondence: Jong S. Kim

Department of Neurology, Asan Medical Center, University of Ulsan College of Medicine, 88 Olympic-ro 43-gil, Songpa-gu, Seoul 05505, Korea

Tel: +82-2-3010-3440; Fax: +82-2-474-4691

Email: jongskim@amc.seoul.kr

Received: February 11, 2016

Revised: March 10, 2016

Accepted: March 14, 2016

This study was supported by a grant from the Republic of Korea's Ministry for Health, Welfare, and Family Affairs (HI14C1985).

The authors have no financial conflicts of interest. 